\title{
Smart growth of Lhasa
}

\author{
Yaoyu Zhang \\ School of North China Electric Power University Baoding, Baoding 071000, China; \\ 790718045@qq.com
}

Keywords: Analytic Hierarchy Process, Sustainable Development Metric, Lhasa, smart growth

\begin{abstract}
With the popularity of smart growth raising worldwide, the sustainable development of cities has attracted more and more attention. We define Sustainable Development Metric (SDM) as our metric to describe the smart growth in Lhasa. The three-hierarchy structure is built and there are 1 first level index (SDM), 3 second level indexes and 21 third level indexes. In addition, we build a AHP model whose evaluation matrix is constructed by grey relational analysis.
\end{abstract}

\section{Introduction}

Under the blue sky and white clouds, leading a smart life in the community is really a happy thing. However, along with the advancement of global urbanization, and consumption of natural resources and energy in the past 100 years, the deterioration of the global environment become worse and worse. Thus, many communities are implementing smart growth initiatives in an effort to consider long range, sustainable planning goals. Smart growth development is based on 10 key principles and focus on economically prosperous, socially equitable, and environmentally sustainable.

\section{The method}

In order to obtain the metric to measure the success of smart growth of Lhasa, we find the 42 indicators mainly fall into three categories by cluster analysis of SPSS. These three categories satisfy the principle of sustainable development. Then we get rid of a few unrepresentative, repetitive indexes and our final evaluation system has 1 first-level indicator, 3 secondary indexes, 21 tertiary indicators. The three-hierarchy structure which contains second level and third level is shown in Figure 1 as follow:

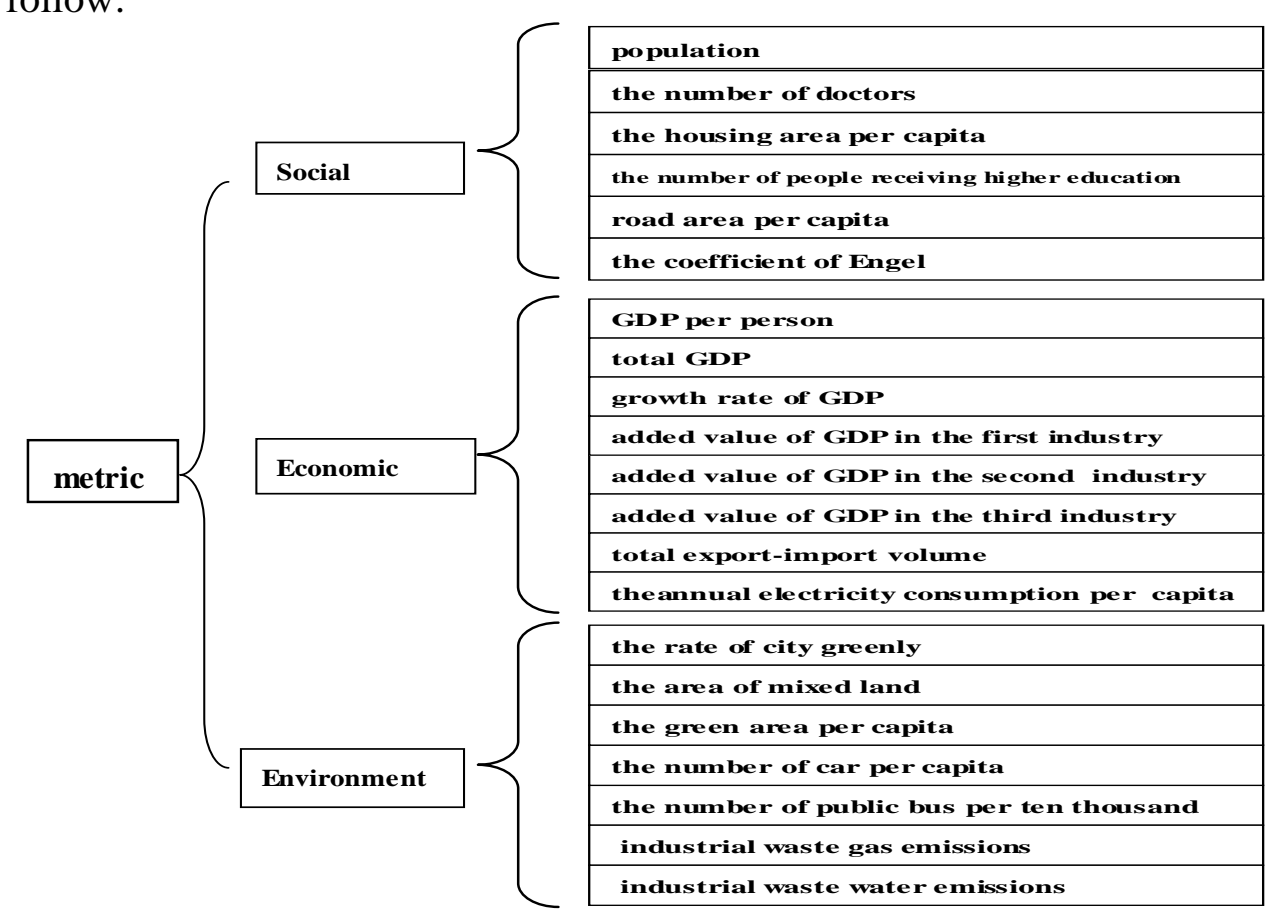

Figure 1. The three-hierarchy structure of our model 
When we try to define the weight of mainly three aspects as the second class index and the weight of several third class index, we choose the Analytic Hierarchy Process (AHP) and grey relational analysis as the way to conform the weighting coefficient of all the indicators in the evaluation system.

According to the correlation degree of $x_{i}$ to $x_{0}$ and using the pairwise comparison method and one-nine method to construct judging matrix $\mathrm{A}=\left(a_{i j}\right)$

$$
a_{i k} * a_{k j}=a_{i j}
$$

- Calculate the eigenvalues and eigenvectors

The greatest eigenvalue of matrix $\mathrm{A}$ is $\lambda_{\max }$, and the corresponding eigenvector is $\mathrm{u}=\left(u_{1_{n}} u_{2} u_{3_{n}} \ldots u_{n}\right)^{T}$. Then we normalize the $u$ by the expression:

$$
x_{i}=\frac{u_{i}}{\sum_{i=0}^{n} u_{j}}
$$

- Do the consistency check

The indicator of consistency check formula:

$$
\mathrm{CI}=\frac{\lambda_{\max }-n}{n-1}
$$

Where $n$ denotes the exponent number of matrix.

The expression of consistency ratio:

$$
\mathrm{CR}=\frac{C I}{R I}
$$

\section{- Determination of SDM}

We have confirmed the weighting coefficient of all the indicators in the evaluation system and now we quantify the metric to measure the success of smart growth of Lhasa.

$C_{i}$ denotes the weight of $i^{\text {th }}$ second level factors, $A_{j}$ is the weight of $j^{\text {th }}$ third level factor, and $E_{j}$ denotes the $j^{\text {th }}$ third level factor.

The evaluation metric $Y$ should be:

$$
\mathrm{Y}=\sum_{i=1}^{3} C_{i} * \sum_{j=1}^{m} A_{j} * E_{j}
$$

We define the metric Y as Sustainable Development Metric (SDM) to describe the successful degree of smart growth and evaluate the sustainable degree. Furthermore, based on three E's of sustainability and the 10 principles of smart growth in the topic, we summary concisely the plans of two cities as the following points:

$\checkmark$ Build roads and strengthen infrastructure construction.

$\checkmark$ Poverty alleviation and safeguard social fairness.

$\checkmark$ Build cultural tourism creative-park.

$\checkmark$ Set up characteristic town in Lhasa.

- Collecting data

We search the statistics in Bureau of Statistics (NBS) and find out the values of 21 indexes in last section. The values are shown in Table 1. 
Table 1. Original data of Lhasa from 2011 to 2015

\begin{tabular}{|c|c|c|c|c|c|}
\hline Third level index & 2011 & 2012 & 2013 & 2014 & 2015 \\
\hline $\mathrm{X}_{1}$ & 57.61 & 50 & 60.12 & 52.73 & 53.03 \\
\hline $\mathrm{X}_{2}$ & 0.21 & 0.15 & 0.17 & 0.17 & 0.21 \\
\hline $\mathrm{X}_{3}$ & 0.218018 & 0.773 & 0.959747 & 1.396738 & 1.739959 \\
\hline $\mathrm{X}_{4}$ & 2.5765 & 1.9579 & 1.9059 & 2.4936 & 2.1358 \\
\hline $\mathrm{X}_{5}$ & 3.1 & 4.4 & 5.1 & 5.7 & 6.3 \\
\hline $\mathrm{X}_{6}$ & 0.48 & 0.45 & 0.41 & 0.42 & 0.38 \\
\hline $\mathrm{X}_{7}$ & 3.860788 & 5.202 & 5.071025 & 6.589228 & 7.104092 \\
\hline $\mathrm{X}_{8}$ & 222.42 & 260.1 & 304.87 & 347.45 & 376.73 \\
\hline $\mathrm{X}_{9}$ & 0.15879 & 0.169409 & 0.172126 & 0.139666 & 0.084271 \\
\hline $\mathrm{X}_{10}$ & 9.99 & 10.8 & 11.73 & 12.94 & 13.8 \\
\hline $\mathrm{X}_{11}$ & 75.21 & 90.7 & 107.56 & 127.75 & 140.95 \\
\hline $\mathrm{X}_{12}$ & 137.22 & 158.7 & 185.58 & 206.76 & 221.98 \\
\hline $\mathrm{X}_{13}$ & 1307.42 & 2533.25 & 3205.15 & 2076.29 & 2640.55 \\
\hline $\mathrm{X}_{14}$ & 12.955 & 16.63 & 20.41 & 23.77 & 27.76 \\
\hline $\mathrm{X}_{15}$ & 34.96 & 35.32 & 36.3 & 37.60 & 38 \\
\hline $\mathrm{X}_{16}$ & 23.5 & 29.6 & 35.3 & 45.2 & 65.3 \\
\hline $\mathrm{X}_{17}$ & 7.32 & 7.65 & 8.64 & 9.63 & 10.32 \\
\hline $\mathrm{X}_{18}$ & 0.2293 & 0.339 & 0.325017 & 0.436374 & 0.504243 \\
\hline $\mathrm{X}_{19}$ & 0.008505 & 0.01 & 0.008483 & 0.009862 & 0.009806 \\
\hline $\mathrm{X}_{20}$ & 853 & 898 & 930 & 865 & 954 \\
\hline $\mathrm{X}_{21}$ & 295 & 306 & 333 & 326 & 368 \\
\hline
\end{tabular}

Notice: $X_{1} \sim X_{21}$ represnt population, the number of doctors, the housing area per capita, the number of receive higher Education, road area per capita, the coefficient of Engel, GDP per person, total GDP, growth rate of GDP, added value of GDP in the first industry, added value of GDP in the second industry, added value of GDP in the third industry, total export-import volume, the annual electricity consumption per capita, the rate of city greenly, the area of mixed land, the green area per capita, the number of cars per capita, the number of public buses per ten thousand persons, industrial waste gas emissions and industrial waste water emissions.

- Results

Based on the data we have already collected in Table 1, we solve the model and obtain the results. The results of Lhasa are shown as follow:

Table 2. The index in and Lhasa and Geneva (2011-2015)

\begin{tabular}{cccccc}
\hline & 2011 & 2012 & 2013 & 2014 & 2015 \\
\hline Lhasa & 0.0425 & 0.2656 & 0.4449 & 0.7513 & 0.7628 \\
\hline
\end{tabular}


- Analysis:

The results of index (SDM) from 2011 to 2015 are expressed in a line chart as Figure 2.

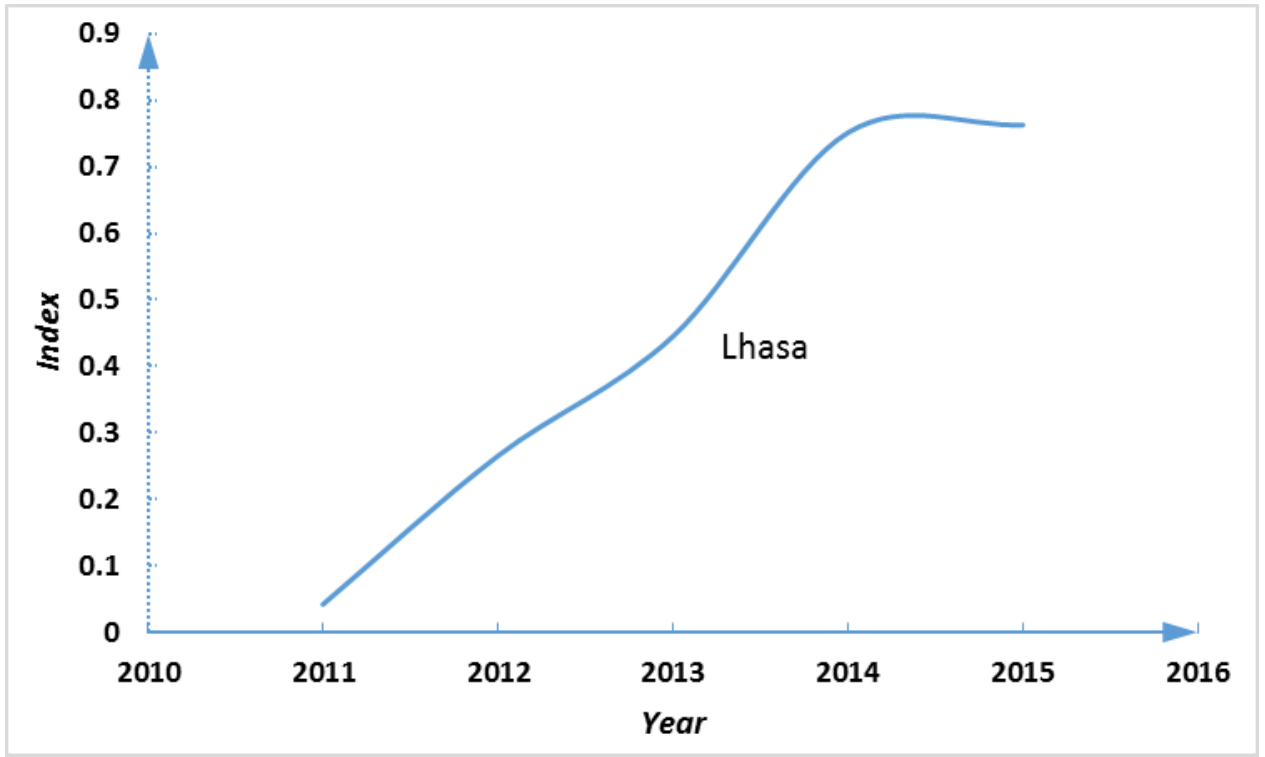

Figure 2. The results of SDM in Lhasa from 2011 to 2015

We can see that Lhasa's index increase at first and then become leveling off. In summary, the current plans greatly meet the principles of smart growth, and the metrics of sustainability in Lhasa on the rise as a whole. The average annual growth rate of index in Lhasa is $265.7 \%$. So the success of the plan carried out in Lhasa is high.

\section{Summary}

From the analysis and the calculation of the index of Lhasa, the degree of sustainability in Lhasa increase first, and the growth rate begin to lower after 2015. The government must find some way to maintain the sustainable development of Lhasa, such as adjusting industrial emissions and increasing the number of urban basic transportation.

\section{References}

[1] EPA,“This is Smart Growth.” 2016 https://www.epa.gov/smartgrowth/smart-growth-publication Reference to a book:

[2] Alp Tanyas Mehmet. Evaluating radio frequency identification investments using fuzzy cognitive maps. Journal of Multiple-Valued Logic and Soft Computing, 2008, 14:277-295

[3] http://en.wikipedia.org/wiki/Analytic_hierarchy_process

[4] Diaz C, Conde J E, Estevez D, et al. "Application of multivariate analysis and artificial neural networks for the differentiation of red wines from the canary islands according to the island of origin," Agric Food Chern, voI.51,pp.4303-4307,2001 